\title{
NONLINEAR OPTICAL PROPERTIES AND OPTICAL POWER LIMITING OF POLY (3HT- Co - Th) - PMMA POLYMER BLEND FILMS
}

\author{
Imad Al - Deen Hussein Ali Al - Saidi ${ }^{*}{ }^{\circledR}$, Hussein Falih Hussein ${ }^{1}$, Numan Sleem
} Hashim ${ }^{1}$

${ }^{* 1}$ Department of Physics, College of Education for Pure Sciences, University of Basrah, Basrah, Iraq

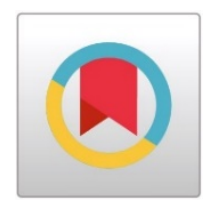

DOI: https://doi.org/10.29121/IJOEST.v5.i1.2021.142

Article Type: Research Article

Article Citation: Imad Al - Deen

Hussein Ali Al - Saidi, Hussein Falih

Hussein, and Numan Sleem Hashim.

(2021). NONLINEAR OPTICAL

PROPERTIES AND OPTICAL POWER

LIMITING OF POLY (3HT- Co - Th) -

PMMA POLYMER BLEND FILMS.

International Journal of Engineering

Science Technologies, 5(1), 1-10.

https://doi.org/10.29121/IJOEST.v

5.11.2021.142

Received Date: 10 December 2020

Accepted Date: 08 January 2021

Keywords:

Copolymer

Polymer Blend Films

Nonlinear Optical Properties

Optical Power Limiting

Z - Scan Technique

\section{ABSTRACT}

Poly (3 - Hexylthiophene - Co - Thiophene) copolymer was prepared using the addition polymerization method and poly (3HT- Co - Th) - PMMA polymer blend films were prepared using the casting method. The nonlinear optical properties and the behavior of the optical power limiting of the prepared films were studied using the $\mathrm{z}$ - scan technique for different weight ratios of the copolymer poly (3HT- Co - Th). In the present work, a continuous wave (CW) diode - pumped solid - state laser (DPSSL) of wavelengths $532 \mathrm{~nm}$ was used for the irradiation of the prepared film samples. The nonlinear optical parameters such as, the nonlinear refractive index (n2), the nonlinear absorption coefficient $(\beta)$, and the third - order nonlinear optical susceptibility $\left(\chi^{(3)}\right)$ of the polymer blend poly (3HT- Co Th) - PMMA films were determined for different weight ratios of the copolymer poly (3HT- Co - Th). It is observed that the polymer blend poly (3HT - Co - Th) - PMMA films exhibit saturable absorption (SA) and self defocusing effects, and this gives an indication that both, the nonlinear refractive index (n2) and the nonlinear absorption coefficient $(\beta)$, have negative values. The obtained results indicate that the prepared polymer blend poly (3HT - Co - Th) - PMMA films are promising materials and can be considered as suitable materials for different optical and electronic applications.

\section{INTRODUCTION}

Nonlinear optical (NLO) properties of different optical materials have received much attention because of their several applications such as, optical power limiting, optical switching, light - emitting diodes, solar cells, optical sensors, and in photonic and optoelectronic devices [1 - 17]. Thiophone is one of these important materials. It is a conjugate polymer and has attractive properties for many optical and electronic applications, such as: Solubility in the organic solvents, flexibility in the preparation, and absorbance in the ultraviolet and visible spectral regions, high electrical conductivity, good environmental stability, and high optical damage thresholds [8, 18]. Thiophene and 3 Hexylthiophene were used to prepared the copolymer poly (3HT- Co - Th). In order to obtain a new polymer suitable for the optical and optoelectronic applications, the prepared copolymer is adding to the poly (methyl methacrylate) (PMMA) polymer. Such prepared polymer blend shows high absorption in the range of the visible and the ultraviolet of the electromagnetic spectrum. It is observed that the addition of the prepared copolymer to the PMMA polymer causes significant modification in the optical properties of the PMMA polymer. It is found, in the present study, that

(C) 2021 The Author(s). This is an open access article distributed under the terms of the Creative Commons Attribution License, which permits unrestricted use, distribution, and reproduction in any medium, provided the original author and source are credited. 
Nonlinear Optical Properties and Optical Power Limiting of Poly (3HT- Co - Th) - PMMA Polymer Blend Films

the optical properties of the prepared polymer blend poly (3HT- Co - Th) - PMMA films are depended on the weight ratio of the added copolymer poly (3HT - Co - Th) to the PMMA polymer and their properties are changed with changing this weight ratio.

Optical limiting (OPL) behavior is an important nonlinear effect can be used for the optical limiter device to protect the human eyes and the other sensitive optical devices (such as, optical switches and optical sensors), from the optical damages due to the intense laser beams, that may be caused those damages. The optical limiter is working as an attenuator for the incident optical radiation (such as the laser beam radiation) on these devices. In the nonlinear optical materials, the output power (or the intensity) of the laser beam tends to increase with increasing the input power (or the intensity) of the laser beam until it reaches a value called the threshold optical power $\left(\mathrm{P}_{\text {th }}\right)$, then the output power starts to stabilize at a constant value as the input power continuing to increase [19 - 24].

There are several techniques for measuring the nonlinear optical properties of the optical materials. The $\mathrm{z}$ - scan technique is one of these techniques, which is commonly used for the measurements of the nonlinear optical properties of the optical materials due to its advantages such as, the simplicity of the experimental setup and the optical measurements, as well as it is easily to interpret the results that obtained from the optical measurements. Moreover, this technique is sensitive to most the nonlinear optical effects such as, self - focusing, self - defocusing, nonlinear refraction, nonlinear saturable absorption (SA), and optical limiting [25, 29]. This technique can be used to measure the nonlinear refractive index $\left(\mathrm{n}_{2}\right)$, the nonlinear absorption coefficient $(\beta)$, and the third - order of the nonlinear optical susceptibility $\left(\chi^{(3)}\right)$ of many optical materials. There are two types of the $\mathrm{z}$ - scan technique. The first type is called, close - aperture $\mathrm{z}$ - scan, is used to scan the beam of the laser along the $\mathrm{z}$ - axis of the closed (partially open) aperture and measure the nonlinear refractive index $\left(\mathrm{n}_{2}\right)$. While the second type is called, the open - aperture $\mathrm{z}$ - scan (the aperture is completely open or it is removed from the $\mathrm{z}$ - scan system) and is used to measure the nonlinear absorption coefficient $(\beta)$. In addition to being used to measure the real and imaginary parts of the third - order nonlinear optical susceptibility $\left(\chi^{(3)}\right)$, this technique is also used to study the properties of the optical power limiting.

\section{EXPERIMENTAL METHODS AND MEASUREMENTS}

The copolymer poly (3HT - Co - Th) was prepared by using the addition polymerization method. The monomers $3 \mathrm{HT}$ and Th were purchased from the Aman International Industrial Company, India. Two different weight ratios of the 3HT and TH monomers were mixed together. The poly (3HT - Co - Th) - PMMA polymer blend film samples were prepared for different weight ratios by using the casting method. $4 \mathrm{gm}$ of poly(methylmethacrylate) (PMMA) polymer was dissolved in $10 \mathrm{ml}$ of Chloroform and the mixture was stirred for 3 hours until the polymer completely dissolved and homogenous solution produced. Then, different percentage weight ratios of the copolymer poly (3HT - Co - Th), $0.033 \%, 0.040 \%, 0.046 \%, 0.053 \%$, and $0.060 \%$ were added to the PMMA solution. The produced solution was stirred until the two polymers mixed together and homogeneous solutions were formed. The produced solutions of the poly (3HT - Co - Th) - PMMA polymer blend at different weight ratios of the copolymer poly (3HT - Co - Th) were cast on glass slides of $1 \mathrm{~mm}$ thickness and left to dry progressively and hard poly (3HT Co - Th) - PMMA polymer blend films were obtained. The average thickness of these films was around $1 \mathrm{~mm}$.

The absorbance $(\mathrm{A})$ and the transmittance $(\mathrm{T})$ spectra of the prepared polymer film samples were measured by using Cecil UV - Visible double - beam spectrophotometer (Model CE -7500) of the wavelength range $190-1100 \mathrm{~nm}$.

For measuring the nonlinear optical properties and determining the associated nonlinear optical parameters of the poly (3HT - Co - Th) - PMMA polymer blend films, the $\mathrm{z}$ - scan technique was used. Fig.1. shows the schematic diagram of the $\mathrm{z}$ - scan experimental setup used in the present work for the measurements of the nonlinear optical properties of the prepared poly (3HT - Co - Th) - PMMA polymer blend films.

The laser used in the $\mathrm{z}$ - scan experiments was a continuous wave (CW) diode - pumped solid - state laser (DPSSL) of a Gaussian beam at $\lambda=532 \mathrm{~nm}$ wavelength. The laser is of adjustable output power over the range $0-100 \mathrm{~mW}$. A converging lens (L) of focal length $5 \mathrm{~cm}$ was used to focus the laser beam on the film sample. The radius of the laser beam $\left(\mathrm{w}_{0}\right)$ at the beam waist is approximately $18 \mu \mathrm{m}$, and the intensity of the laser beam is calculated and its value is $I_{0}=1.94 \mathrm{~kW} / \mathrm{cm}^{2}$. The corresponding Rayleigh range $\left(Z_{R}\right)$ is $1.91 \mathrm{~mm}$, which is consisted with the $\mathrm{z}$ - scan condition that the length of the sample (L) must be less than the Rayleigh range $\left(Z_{R}\right)$, namely, $L<<R$ [22]. The output laser beam was spitted into two parts by the beam splitter (BS). The first part of the laser beam is directed toward the photo-detector $\mathrm{D}_{1}$, which was used to measure the power of the incident laser beam on the sample. While the second 
part of the laser beam was focused on the film sample by the convergence lens (L) and passes through the sample. Then the laser beam passes through the narrow aperture and incident on the photo-detector $\mathrm{D}_{2}$, which was placed behind the aperture to measure the power of the transmitted beam. The radius of the aperture, which used in the closed (partially open) aperture, is $1 \mathrm{~mm}$.

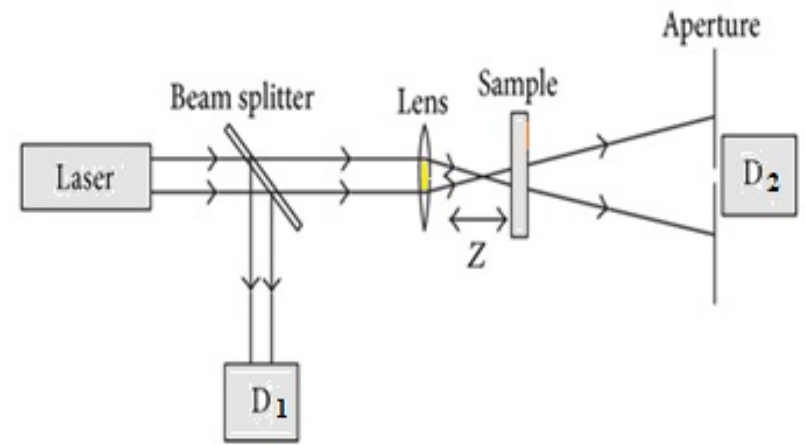

Figure 1: Schematic diagram of the $\mathrm{z}$ - scan experimental setup used for the measurements of the nonlinear optical properties of the prepared film samples.

\section{RESULTS AND DISCUSSION}

UV - Visible absorbance spectra of the poly (3HT - Co - Th) - PMMA polymer blend films for different weight ratios of the copolymer poly (3HT - Co - Th) were recorded over the wavelengths $300-900 \mathrm{~nm}$ by using the double - beam spectrophotometer, as shown in Fig. 2. The spectra show that the high absorbance peaks are located around the wavelength $466 \mathrm{~nm}$. The values of absorbance are in the range of $0.05-0.34$ (Arb. Units) for the weight ratios range $0.033 \%-0.060 \%$ of the copolymer poly (3HT - Co - Th). It can be clearly seen that the value of the absorbance of the poly (3HT - Co - Th) - PMMA polymer blend film increases with increasing the weight ratio of the copolymer poly (3HT - Co - Th).

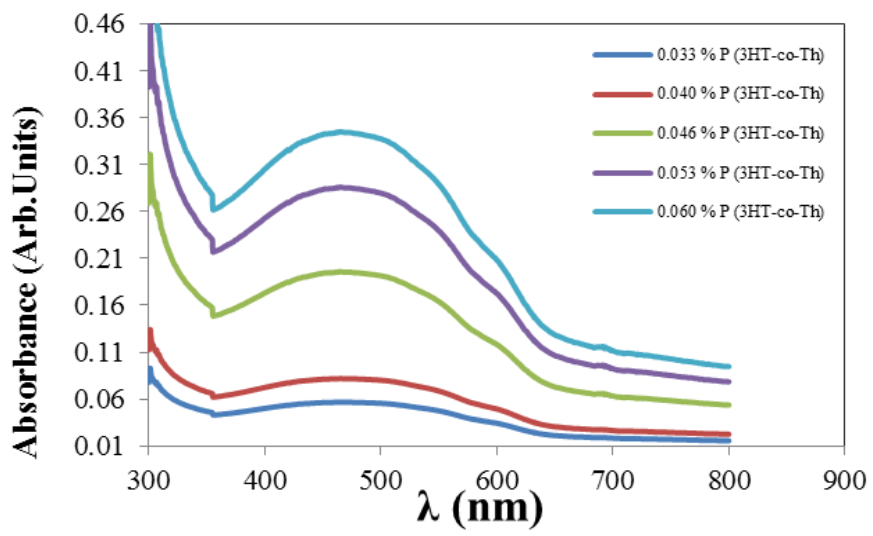

Figure 2: UV- Visible absorbance spectra of the poly (3HT - Co - Th) - PMMA polymer blend film at different weight ratios of the copolymer poly (3HT - Co - Th).

The normalized transmittance curves of the closed - aperture laser beam $\mathrm{z}$ - scan, the open - aperture laser beam $\mathrm{z}$ - scan, and the pure nonlinear refraction of the p (3HT - Co - Th) - PMMA polymer blend film at different weight ratios of the copolymer poly (3HT - Co - Th) were measured and are shown in Figs.3 (a) - (c), respectively. The contribution of the nonlinear refraction only (the pure normalized transmittance curves in Fig. 3 (c)) was obtained by dividing the data of the normalized transmittance of the closed - aperture laser beam $\mathrm{z}$ - scan by the data of the normalized transmittance of the open - aperture laser beam z - scan. We noticed from Fig. 3 (a) that the normalize transmittance curve starts with a peak in the negative part of the $\mathrm{z}$ - axis to the valley in the positive part of the $\mathrm{z}$ - axis, this means that the normalized transmittance curve has a peak - to - valley feature. Such behavior is an indication of the exhibiting of self - defocusing effect of the laser beam when passing through the polymer film 
samples, and thus these film samples have negative values of the nonlinear refractive index $\left(\mathrm{n}_{2}<0\right)$. It is clear from Fig. 3 (b) that there is an increase in the value of the normalized transmittance when the sample approaches the focal point, and this gives an indication that the prepared film samples in the present study exhibit saturable absorption (SA) when the laser beam intensity increases, and this means that these film samples have negative values of the nonlinear absorption coefficient $(\beta<0)$.
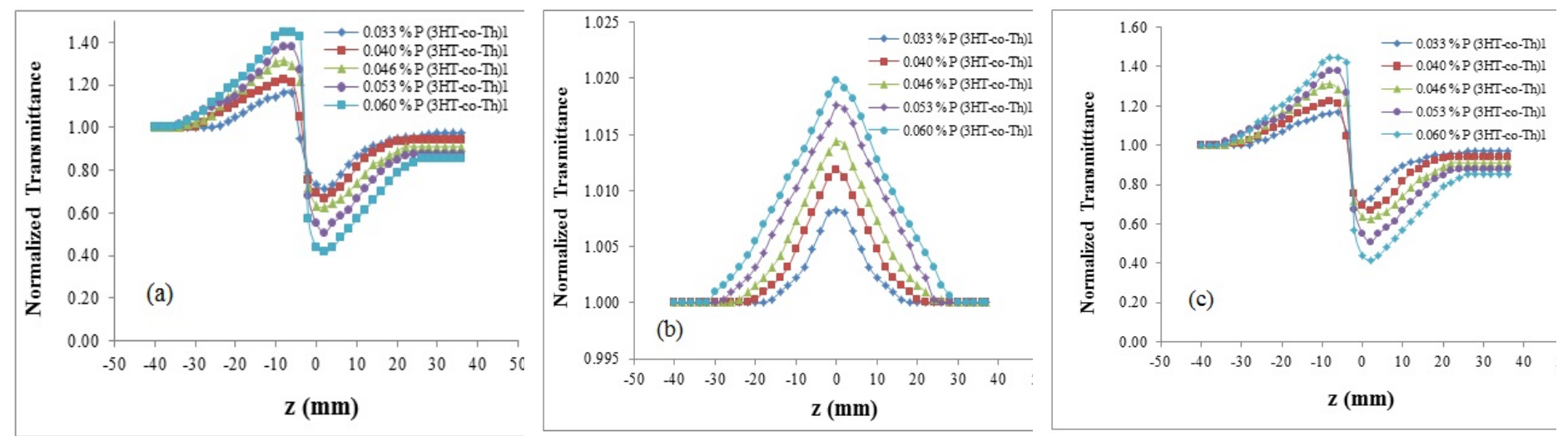

Figure 3: Normalized transmittance curves for the poly (3HT - Co - Th) - PMMA polymer blend film at different weight ratios of the copolymer poly (3HT - Co - Th). (a) Closed - aperture z - scan. (b) Open - aperture z - scan. (c)

Pure nonlinear refraction.

The nonlinear optical parameters, $\mathrm{n}_{2}, \beta$, and the real $\left(\operatorname{Re}\left(\chi^{(3)}\right)\right)$ and the imaginary $\left(\operatorname{Im}\left(\chi^{(3)}\right)\right)$ parts of the third - order nonlinear optical susceptibility $\left(\left(\chi^{(3)}\right)\right)$ can be determined from the following relations.

By Using the difference between peak and valley transmittances for the normalized transmission curve i.e., $\Delta \mathrm{T}_{\mathrm{p}-\mathrm{v}}=\mathrm{T}_{\mathrm{p}}-\mathrm{T}_{\mathrm{v}}$, the phase difference $\Delta \phi_{\mathrm{o}}$ can be determined according to the following relation [25, 26]:

$$
\Delta \mathrm{T}_{\mathrm{p}-\mathrm{v}}=0.406(1-\mathrm{S})^{0.25}\left|\Delta \phi_{0}\right|
$$

where $S$ is the linear transmittance of the aperture and given by:

$$
\mathrm{S}=1-\exp \left(-2 \mathrm{r}_{\mathrm{a}}^{2} / \mathrm{wa}^{2}\right)
$$

where $\mathrm{ra}_{\text {is }}$ the radius of the aperture and $\mathrm{w}_{\mathrm{a}}$ is the radius of the laser beam at the entrance of the aperture and given by:

$$
\mathrm{w}_{\mathrm{a}}=\mathrm{w}_{\mathrm{o}}\left[1+\left(\frac{\lambda \mathrm{z}_{\mathrm{a}}}{\pi \mathrm{w}_{\mathrm{o}}{ }^{2}}\right)^{2}\right]^{1 / 2}
$$

where $\lambda$ is the wavelength of the laser beam.

Figure 4: shows the calculated peak - valley transmittance difference $\left(\Delta \mathrm{T}_{\mathrm{p}-\mathrm{v}}\right)$ as a function of the copolymer poly (3HT - Co - Th) weight ratio. It is seen that the value of $\Delta \mathrm{T}_{\mathrm{P}-\mathrm{v}}$ increases with increasing the weight ratio of the copolymer poly (3HT - Co - Th). 
Imad Al - Deen Hussein Ali Al - Saidi, Hussein Falih Hussein, and Numan Sleem Hashim

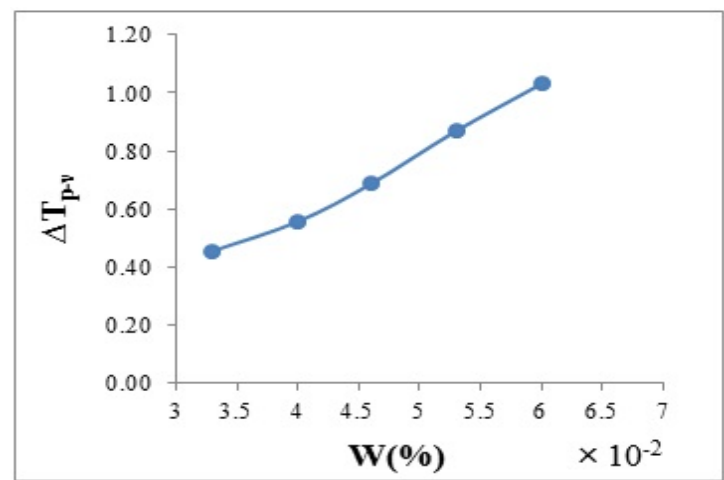

Figure 4: Variation of $\Delta \mathrm{T}_{\mathrm{p}-\mathrm{v}}$ with the weight ratio of the copolymer poly (3HT - Co - Th).

The nonlinear refractive index $\left(\mathrm{n}_{2}\right)$ is given by the following relation [26]:

$$
\mathbf{n}_{2}=\frac{\Delta \varnothing_{0} \lambda}{2 \pi \mathbf{I}_{0} \mathbf{L}_{\mathrm{eff}}}
$$

where $\mathrm{I}_{0}$ is the intensity of the laser beam at focus $(\mathrm{z}=0)$, and given by:

$$
\mathbf{I}_{0}=\frac{2 \mathbf{P}_{0}}{\pi \omega_{0}^{2}}
$$

where $\mathrm{P}_{0}$ is the laser input power.

The induced refractive index change $(\Delta \mathrm{n})$ of material is given by the relation:

$$
\Delta \mathrm{n}=\mathrm{n}_{2} \mathrm{I}
$$

where I is the intensity of the incident laser beam.

The nonlinear absorption coefficient $(\beta)$ is given by the following relation:

$$
\beta=\frac{2 \sqrt{2}}{\mathrm{I}_{0} \mathrm{~L}_{\mathrm{eff}}} \Delta \mathrm{T}
$$

where $\Delta \mathrm{T}$ is the normalized transmittance difference between peak at the focal point $(\mathrm{z}=0)$ in the open aperture $\mathrm{z}$ - scan normalized transmittance curve and the baseline, and $\mathrm{L}_{\text {eff }}$ is the effective length of the sample and given by:

$$
\mathrm{L}_{\mathrm{eff}}=\left(1-\exp \left(-\alpha_{0} \mathrm{~L}\right)\right) / \alpha_{0}
$$

where $\alpha_{0}$ is the linear absorption coefficient of the medium.

The nonlinear optical parameters $n_{2}$ and $\beta$ are associated with the real $\left(\operatorname{Re}\left(\chi^{(3)}\right)\right)$ and the imaginary $\left(\operatorname{Im}\left(\chi^{(3)}\right)\right)$ parts of the third - order nonlinear optical susceptibility $\left(\chi^{(3)}\right)$, and provide important information about the properties of the material. The real and the imaginary parts of the third - order nonlinear optical susceptibility can be determined by using the following relations [30]: 
Nonlinear Optical Properties and Optical Power Limiting of Poly (3HT- Co - Th) - PMMA Polymer Blend Films

$$
\begin{aligned}
& \operatorname{Re}\left[\chi^{(3)}\right](\mathrm{esu})=10^{-4} \frac{\varepsilon_{0} \mathrm{c}^{2} \mathrm{n}_{0}{ }^{2} \mathrm{n}_{2}}{\pi} \quad\left(\mathrm{cm}^{2} / \mathrm{W}\right) \\
& \operatorname{Im}\left[\chi^{(3)}\right](\mathrm{esu})=10^{-2}-\frac{\bar{\varepsilon}_{0} \mathrm{c}^{2} \mathrm{n}_{0}{ }^{2} \lambda \beta}{4 \pi^{2}} \quad(\mathrm{~cm} / \mathrm{W})
\end{aligned}
$$

The complex third - order nonlinear optical susceptibility $\left(\chi^{(3)}\right)$, can be described by the following relation:

$$
\left|\chi^{(3)}\right|=\left[\left(\operatorname{Re}\left(\chi^{(3)}\right)\right)^{2}+\left(\operatorname{Im}\left(\chi^{(3)}\right)\right)^{2}\right]^{1 / 2}
$$

The nonlinear refractive index $\left(\mathrm{n}_{2}\right)$, the nonlinear absorption coefficient $(\beta)$, and the third - order nonlinear optical susceptibility $\left(\left|\chi^{(3)}\right|\right)$ were plotted as a function of the weight ratio of the copolymer poly (3HT - Co - Th), as shown in Figs. 5, 6 and 7, respectively. The calculated values of the optical parameters of the prepared poly (3HT Co - Th) - PMMA polymer blend film for different weight ratios of the copolymer poly (3HT - Co - Th), are summarized in Table 1. It is clearly noticed from this table; the values of the nonlinear optical parameters increase with increasing the weight ratio of the copolymer poly (3HT - Co - Th).

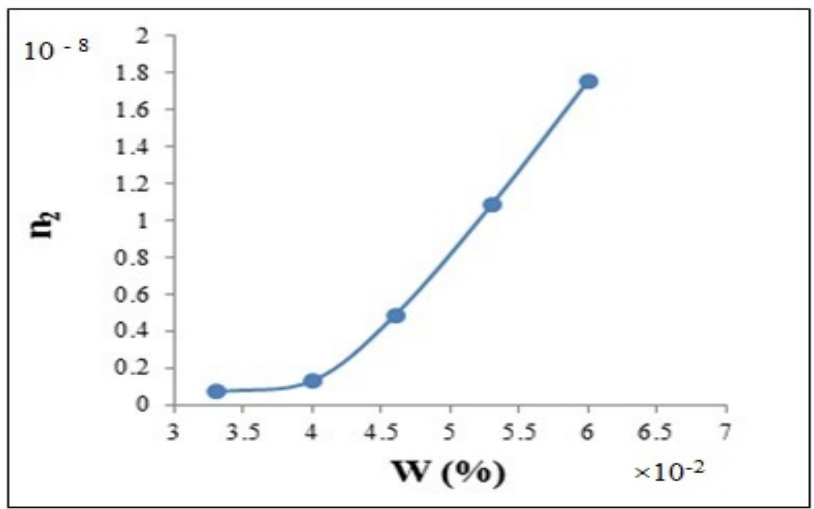

Figure 5: The nonlinear refractive index $\left(\mathrm{n}_{2}\right)$ of the poly (3HT - Co - Th) - PMMA polymer blend film as a function of the weight ratio of the copolymer poly (3HT - Co - Th).

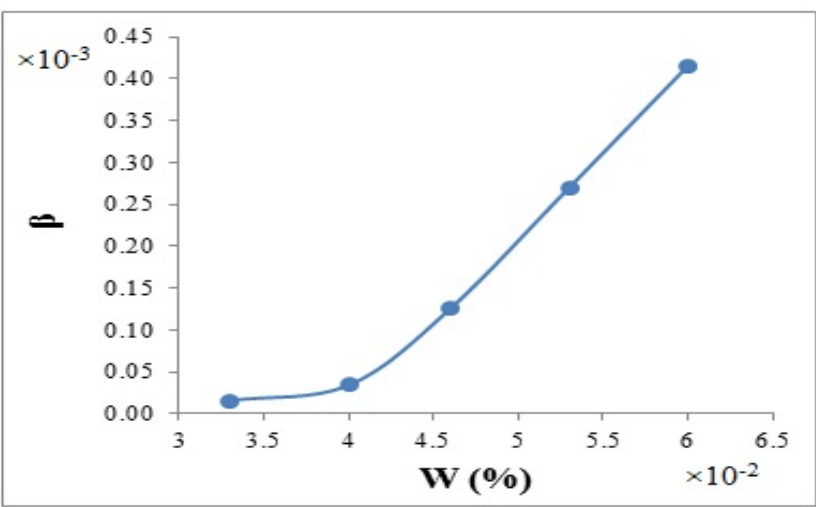

Figure 6: The nonlinear absorption coefficient $(\beta)$ of the poly (3HT - Co - Th) - PMMA polymer blend film as a function of the weight ratio of the copolymer poly (3HT - Co - Th). 
Imad Al - Deen Hussein Ali Al - Saidi, Hussein Falih Hussein, and Numan Sleem Hashim

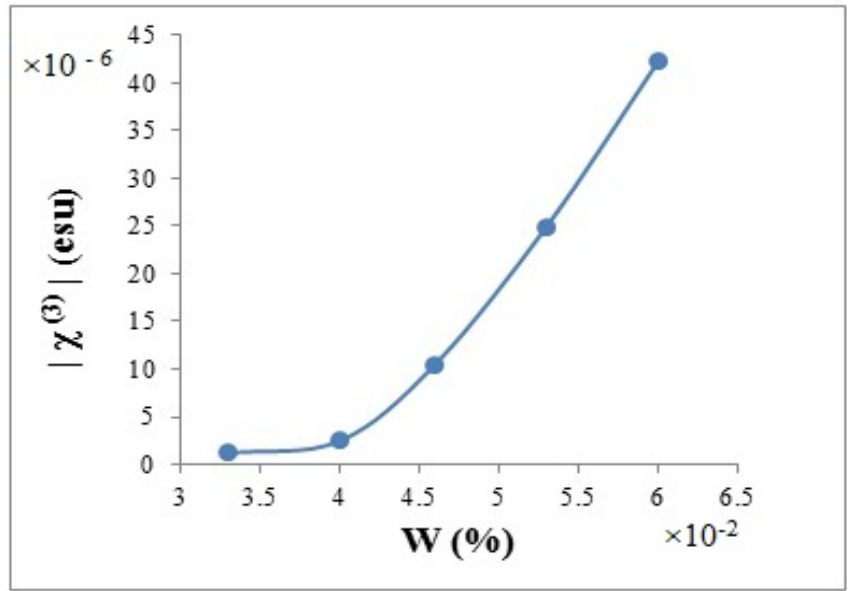

Figure 7: The nonlinear third - order optical susceptibility $\left(\left|\chi^{(3)}\right|\right)$ of the poly (3HT - Co - Th) - PMMA polymer blend film as a function of the weight ratio of the copolymer poly (3HT - Co - Th).

Table 1: The calculated values of the optical parameters of poly (3HT - Co - Th) - PMMA polymer blend film for five different weight ratios of the copolymer poly (3HT - Co - Th).

\begin{tabular}{|c|c|c|c|c|c|c|c|c|}
\hline $\begin{array}{c}\text { poly (3HT- Co -Th) } \\
(\%)\end{array}$ & $\mathrm{n}_{\mathrm{o}}$ & $\Delta \mathrm{T}_{\mathrm{p}-\mathrm{v}}$ & $\begin{array}{c}\mathrm{n}_{2} \\
\left(\mathrm{~cm}^{2} / \mathrm{W}\right) \\
\times 10^{-8}\end{array}$ & $\begin{array}{c}\Delta \mathrm{n} \\
\times 10^{-4}\end{array}$ & $\begin{array}{c}\beta \\
(\mathrm{cm} / \mathrm{W}) \\
\times 10^{-3}\end{array}$ & $\begin{array}{c}\operatorname{Re} \mid \chi^{(3)} \\
(\mathrm{esu}) \\
\times 10^{-6}\end{array}$ & $\begin{array}{c}\operatorname{Im}\left|\chi^{(3)}\right| \\
(\mathrm{esu}) \\
\times 10^{-6}\end{array}$ & $\begin{array}{c}\left|\chi^{(3)}\right| \\
(\mathrm{esu}) \\
\times 10^{-6}\end{array}$ \\
\hline 0.033 & 1.42 & 0.45 & 0.07 & 0.13 & 0.01 & 0.89 & 0.82 & 1.21 \\
\hline 0.040 & 1.53 & 0.55 & 0.13 & 0.25 & 0.03 & 1.69 & 1.82 & 2.48 \\
\hline 0.046 & 1.90 & 0.68 & 0.48 & 0.95 & 0.12 & 7.22 & 7.65 & 10.5 \\
\hline 0.053 & 2.15 & 0.86 & 1.08 & 2.13 & 0.27 & 17.4 & 17.8 & 24.9 \\
\hline 0.060 & 2.43 & 1.03 & 1.75 & 3.45 & 0.41 & 30.3 & 29.4 & 42.2 \\
\hline
\end{tabular}

The optical power limiting properties of the poly (3HT - Co - Th) - PMMA polymer blend film for different weight ratios of the copolymer poly (3HT - Co - Th) were also studied. Optical power limiting effect was study by using the $\mathrm{z}$ - scan technique. The sample of the poly (3HT - Co - Th) - PMMA polymer blend film was fixed in the $\mathrm{z}$ - scan system after the focal point of the lens, and the laser input power was varied progressively and the corresponding laser output power was recorded by the photo-detector $\mathrm{D}_{2}$. Fig. 8 shows the optical power limiting curves (the laser output power versus the laser input power) for the poly (3HT - Co - Th) - PMMA polymer blend film at different weight ratios of the copolymer poly (3HT - Co - Th). From this figure, it is noticed that the laser input power - laser output power characteristic shape depends on the weight ratio of the copolymer poly (3HT - Co - Th). The poly (3HT - Co Th) - PMMA polymer blend film starts to show more obvious power limiting behavior with increasing the weight ratio of the copolymer poly (3HT - Co - Th). Because an increase in the weight ratio of the copolymer poly (3HT - Co - Th), leads to increase the number of atoms of the polymer film and this causes an increase in the absorption of the incoming photon energy. As a result, the output power of the laser beam will decrease.

The values of the optical power threshold $\left(\mathrm{P}_{\text {th }}\right)$ of the optical power limiter of the prepared poly (3HT - Co - Th) - PMMA polymer blend film was determined for the different weight ratios of the copolymer poly (3HT - Co - Th). The estimated values of the optical power threshold $\left(\mathrm{P}_{\mathrm{th}}\right)$ of the poly (3HT - Co - Th) - PMMA polymer blend film for different weight ratios of the copolymer poly (3HT - Co - Th) are shown in Table 2. It can be noticed that the value of the optical power threshold $\left(\mathrm{P}_{\mathrm{th}}\right)$ depends on the weight ratio of the copolymer poly (3HT - Co - Th), and it decreases with increasing the weight ratio of the copolymer poly (3HT - Co - Th). 
Nonlinear Optical Properties and Optical Power Limiting of Poly (3HT- Co - Th) - PMMA Polymer Blend Films

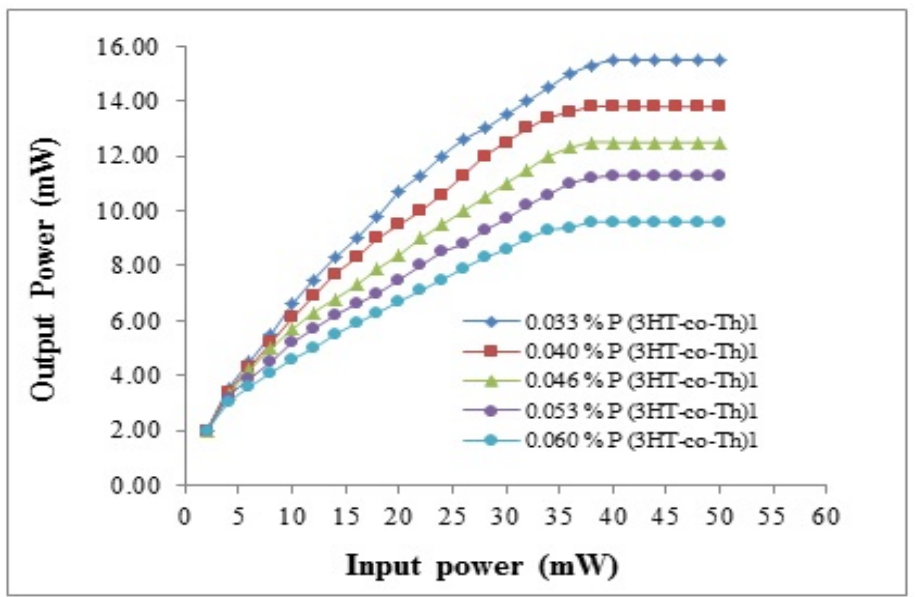

Figure 8: Optical power limiting of the poly (3HT - Co - Th) - PMMA polymer blend film for different weight ratios of the copolymer poly (3HT - Co - Th).

Table 2: The estimated values of the optical power threshold $\left(\mathrm{P}_{\text {th }}\right)$ of the poly (3HT - Co - Th) - PMMA polymer blend film for different weight ratios of the copolymer poly (3HT - Co - Th).

\begin{tabular}{|c|c|}
\hline $\begin{array}{c}\text { Poly (3HT - Co -Th) } \\
(\%)\end{array}$ & $\begin{array}{c}\text { Optical power threshold }\left(\mathrm{P}_{\text {th }}\right) \\
(\mathrm{mW})\end{array}$ \\
\hline 0.033 & 24 \\
\hline 0.040 & 18 \\
\hline 0.046 & 13 \\
\hline 0.053 & 11 \\
\hline 0.060 & 8 \\
\hline
\end{tabular}

\section{CONCLUSIONS}

The copolymer poly (3HT - Co - Th) was prepared by using the addition polymerization method and the film samples of the poly (3HT - Co - Th) - PMMA polymer blend were prepared, for different weight ratios of the copolymer poly (3HT - Co - Th), by using the casting method. The nonlinear optical properties and the behavior of the optical power limiting of the prepared poly (3HT - Co - Th) - PMMA blend polymer film sample for different weight ratios of the copolymer poly ( $3 \mathrm{HT}$ - Co - Th) were studied. The nonlinear optical parameters of the prepared poly (3HT - Co - Th) - PMMA polymer blend film samples, the refractive index $\left(\mathrm{n}_{2}\right)$, the nonlinear absorption coefficient $(\beta)$, and the third - order optical susceptibility $\left(\left|\chi^{(3)}\right|\right)$ were measured by using the $\mathrm{z}$ - scan technique with a continuous wave (CW) diode - pumped solid - state laser (DPSSL) operating at the wavelength $532 \mathrm{~nm}$. It is observed that the prepared poly (3HT - Co - Th) - PMMA polymer blend sample films exhibit the effects of the self defocusing and the nonlinear saturable absorption (SA), which is the indication of the negative values for both the nonlinear refractive index and the nonlinear absorption coefficient $\left(\mathrm{n}_{2}<0\right.$ and $\left.\beta<0\right)$. Obtained results show that increasing of the weight ratio of the copolymer poly (3HT - Co - Th) in the poly (3HT - Co - Th) - PMMA polymer blend film sample will enhance the UV - visible absorption of the polymer blend film sample. Also, increasing of the weight ratio of the copolymer poly (3HT - Co - Th) in the poly (3HT - Co - Th) - PMMA polymer blend film sample will increase the values of the nonlinear optical parameters, $\mathrm{n}_{2}, \beta$, and $\left.\left|\chi^{(3)}\right|\right)$, of this polymer blend film sample.

The optical power limiting behavior of the poly (3HT - Co - Th) - PMMA blend polymer film was studied for different weight ratios of the copolymer poly (3HT - Co - Th). The obtained results showed that the prepared blend polymer films exhibit clear optical power limiting with reasonably low power limiting threshold ( $\left.\mathrm{P}_{\text {th }}\right)$. Results indicate that the prepared poly (3HT - Co - Th) - PMMA polymer blend films are promising candidates, can be used as potential materials for different optical and electronic applications, such as, optical power limiters, optical sensors, solar cells, and other optical and optoelectronic devices. 
Imad Al - Deen Hussein Ali Al - Saidi, Hussein Falih Hussein, and Numan Sleem Hashim

\section{SOURCES OF FUNDING}

This research received no specific grant from any funding agency in the public, commercial, or not-for-profit sectors.

\section{CONFLICT OF INTEREST}

The author have declared that no competing interests exist.

\section{ACKNOWLEDGMENT}

None.

\section{REFERENCES}

[1] G. Harsanyi, Polymer Films in Sensor Applications: Technology, Materials, Devices and Their Applications, (Technomic Publishing Company Inc., Pennsylvania, USA, 1995).

[2] P. Günter, (Ed.), Nonlinear Optical Effects and Materials, (Springer - Verlag,Berlin / Herzberg, Germany, 2000).

[3] D. Y. Kim, H. N. Cho, and C. Y. Kim, "Blue Light Emitting Polymers", Prog. Polymer Sci., 25 (2000) 1089 - 1139.

[4] D. Arivuoli, Fundamentals of Nonlinear Optical Materials, Pramana J. Phys., 57 (2001) 871 - 883.

[5] Ch. Bosshard, J. Hulliger, M. Florsheimer, and P. Gunter, Organic Nonlinear Optical Materials, Advances in Nonlinear Optics, Vol. 1, (Gordon and Breach Publishers, CRC Press Taylor and Francis Group, LLC., Florida, USA, 2001).

[6] H. S. Nalwa, (Ed.), Handbook of Advanced Electronic and Photonic Materials and Devices, (Academic Press, New York, USA, 2001).

[7] R. L Sutherland, (Ed), Handbook of Nonlinear Optics, 2nd Edition, (Dayton,Ohio, USA, 2003).

[8] A. Moliton and R. C. Hiorns, "Review of Electronic and Optical Properties of Semiconducting $\pi$ - Conjugated Polymers: Applications in Optoelectronics”, Polymer Inter. 53 (2004) 1397 - 1412.

[9] R. W. Boyd, Nonlinear Optics, 3rd Edition, (Elsevier Inc., New York, USA. 2008).

[10] M. Helgesen, R. Søndergaard, and F. C. Krebs, "Advanced Materials and Processes for Polymer Solar Cell Devices", J. Mater. Chem., 20 (2009) 36 - 60.

[11] M. Bass, (Ed.), Handbook of Optics: Optical Properties of Materials, Nonlinear Optics, Quantum Optics, Vol. IV, 3rd Edition, (The McGraw - Hill Companies, Inc., New York, USA, 2010).

[12] R. A. Ganeev, Nonlinear Optical Properties of Materials, Springer Series in Optical Sciences, Vol. 174, (Springer, Netherlands, 2013).

[13] O. Ostroverkhova, (Ed.), Handbook of Organic Materials for Optical and Optoelectronic Devices: Properties and Applications, (Woodhead Publishing

Ltd., UK, 2013).

[14] B. D. Guenther, Nonlinear Optics, 2nd Edition, (Oxford University Press, UK,2015).

[15] A. Sacco, M. Gerosa, S. Bianco, L.Mercatelli, R. Fontana, L. Pezzati, M. Quaglio, C. F. Pirri, and A. O. M. Tucci, "Dye - Sensitized Solar Cell for a Solar Concentrator System", Solar Energy, 125 (2016) 307 - 313.

[16] Z. Chai, X. Hu, F. Wang, X. Niu, J. Xie, and Q. Gong, "Review: Ultrafast All - Optical Switching", Adv. Optical Mater., 5 (2016) 665.

[17] Imad Al-Deen Hussein Ali Al-Saidi and Rahad Jabar, "Third - Order Nonlinear Optical Properties and Optical Power Limiting Behavior of Celestin Blue B Dye Doped Polymer Films”, J. Photonic Meter. Tech., 4 (2018) 1 7.

[18] J. R. Reynolds, B. C. Thomson, and T. A. Skotheim, (Eds.), Handbook of Conductivity Polymers: Conjugated Polymers, Perspective, Theory, and New Materials, 4th Edition, (CRC Press, Taylor and Francis Group, LLC., Florida, USA, 2019).

[19] Imad Al-Deen Hussein A. Al-Saidi and Saif Al-Deen Abdulkareem, "Nonlinear Optical Properties and Optical Power Limiting Effect of Giemsa Dye Polymer Films”, Opt. Laser Technol., 82 (2016) 150 - 156. 
Nonlinear Optical Properties and Optical Power Limiting of Poly (3HT- Co - Th) - PMMA Polymer Blend Films

[20] M. J. Moran, C. Y. She, and R. L. Carman, "Interferometric Measurements of Nonlinear Refractive-index Coefficient Relative to CS2 in Laser - System Related Materials”, IEEE J. Quantum Elecrron., QE - 11, (1975) $259-263$.

[21] S. R. Friberg and P. W. Smith, "Nonlinear Optical Glasses for Ultra - Fast Optical Switches”, IEEE J. Quantum Electron., QE - 23, (1987) 2089 - 2094.

[22] E. W. Van Stryland and M. Sheik - Bahae, "Z - Scan Measurements of Optical Nonlinearities", in Characterization Techniques and Tabulations for Organic Nonlinear Materials, M. G. Kuzyk and C. W. Dirk, (Eds.), (Marcel Dekker, Inc., New York, USA, 1998) 655 - 692.

[23] Imad Al-Deen Hussein A. Al-Saidi and Saif Al-Deen Abdulkareem, "Nonlinear Optical Properties and Optical Power Limiting of Leishman Dye Using Z - Scan Technique”, J. Mater. Sci.: Mater. Electron., 20 (2015) 2713.

[24] Imad Al-Deen Hussein A. Al-Saidi and Saif Al-Deen Abdulkareem, "Nonlinear Optical Properties and Optical Power Limiting Behavior of Leishman Dye in Solution and Solid Polymer Film Using Z - Scan”, Optik, 126, (2015) 4299 - 4303.

[25] M. Sheik - Bahae, A. A. Said, and E. W. Van Stryland "High - Sensitivity, Single - Beam n2 Measurements" Opt. Lett. 14 (1989) 955.

[26] M. Sheik - Bahae, A. A. Said, T. Wei, D. J. Hagan, and E. W. Van Stryland, "Sensitive Measurement of Optical Nonlinearities Using a Single Beam", IEEE J. Quantum Electron. QE - 26 (19 90) 760.

[27] Y. R. Shen, The Principle of Nonlinear Optics, (John Wiley and Sons, New York, USA, 1984).

[28] I. A. Al-Saidi and R. G. Harrison, "Self - Focusing of CO2 Laser Radiation in SF6" Appl. Phys. B, 55 (1992) 501.

[29] I. A. Al-Saidi " Laser - Beam Profiles in Liquid CS2: Direct Evidence for Self-Focusing of a Laser Beam in CS2 ", J. Phys. D: Appl. Phys., 32 (1999) 874.

[30] T. Cassano, R. Tommasi, M. Ferrara, F. Babudri, G. M. Farinola, and F. Naso,"Substituent - Dependence of the Optical Nonlinearities in Poly(2,5 - Diakoxy -P - Phenylenevinylene) Polymers Investigated by Z - Scan Technique, Chem.Phys., 272 (2001) 111. 